\title{
Anticorrosion Performance of Epoxy Coating Containing Phytic Acid-Doped Tetraaniline Nanoparticle
}

\author{
Haichao Zhao ${ }^{1, *}$, Tong Liu ${ }^{1,2}$, Chengcheng Jiao ${ }^{1,3}$, Feng Yang $^{3}$ \\ ${ }^{1}$ Key Laboratory of Marine Materials and Related Technologies, Zhejiang Key Laboratory of Marine \\ Materials and Protective Technologies, Ningbo Institute of Materials Technology and Engineering, \\ Chinese Academy of Sciences, Ningbo 315201, P. R. China \\ ${ }^{2}$ National Materials Corrosion and Protection Data Center, University of Science and Technology \\ Beijing, Beijing 100083, China \\ ${ }^{3}$ School of Materials Science and Engineering, Shenyang University of Chemical Technology, Shen \\ Yang, 110142, China \\ *E-mail: zhaohaichao@nimte.ac.cn (H. Zhao)
}

doi: $10.20964 / 2021.07 .04$

Received: 26 February 2021 / Accepted: 11 April 2021 / Published: 31 May 2021

In this work, epoxy coatings containing phytic acid-doped tetraaniline (PATA) nanoparticles for Q235 steel were prepared and their anticorrosive properties were investigated. Synthesized PATA nanoparticles were characterized by scanning electron microscope (SEM), scanning probe microscope (SPM), photoelectronic spectroscopy (XPS), and Raman test. The anti-corrosion properties of coating were studied by the open circuit potential (OCP), electrochemical impedance spectroscopy (EIS), and scanning vibrating electrode technique (SVET). The experimental results showed that the content of the PATA nanoparticle has a positive effect on the barrier ability of the epoxy matrix. The epoxy coating containing $0.25 \mathrm{wt} \%$ of PATA nanoparticles has superior corrosion protection property and a satisfactory self-healing effect. The self-healing effect of PATA/EP coating ascribes to the synergistic effect of the passivation of phytic acid ions and tetraaniline. As an effective anticorrosion filler, the PATA nanoparticle has the potential to apply to the field of corrosion protective coating.

Keywords: tetraaniline; phytic acid; nanoparticle; epoxy coating; corrosion resistance

\section{$\underline{\text { FULL TEXT }}$}

(C) 2021 The Authors. Published by ESG (www.electrochemsci.org). This article is an open access article distributed under the terms and conditions of the Creative Commons Attribution license (http://creativecommons.org/licenses/by/4.0/). 